\title{
Managing Diversity: The Challenges of Inter-University Cooperation in Sustainability Education
}

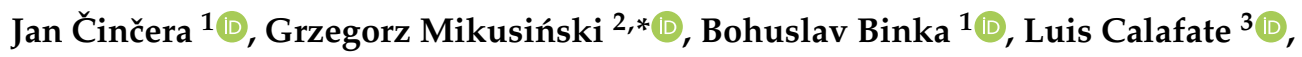

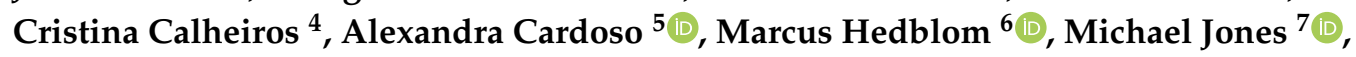 \\ Alex Koutsouris ${ }^{8}$, Clara Vasconcelos ${ }^{5}$ D and Katarzyna Iwińska ${ }^{9}$ \\ 1 Department of Environmental Studies, Faculty of Social Studies, Masaryk University, \\ 60177 Brno, Czech Republic; cincera@mail.muni.cz (J.Č.); binka@fss.muni.cz (B.B.) \\ 2 School for Forest Management, Swedish University of Agricultural Sciences, 73921 Skinnskatteberg, Sweden \\ 3 Department of Biology, Porto University, 4169-007 Porto, Portugal; lcalafat@fc.up.pt \\ 4 Interdisciplinary Centre of Marine and Environmental Research (CIIMAR/CIMAR), University of Porto, \\ 4450-208 Matosinhos, Portugal; cristina@calheiros.org \\ 5 Institute of Earth Sciences, Porto University, 4169-007 Porto, Portugal; alexandra.cardoso@fc.up.pt (A.C.); \\ csvascon@fc.up.pt (C.V.) \\ 6 Department of Forest Resource Management, Swedish University of Agricultural Sciences, \\ 75651 Uppsala, Sweden; marcus.hedblom@slu.se \\ 7 Swedish Biodiversity Centre, Swedish University of Agricultural Sciences, 75007 Uppsala, Sweden; \\ mikejones.psa@gmail.com \\ 8 Department of Agricultural Economics and Rural Development, Agricultural University of Athens, \\ 11855 Athens, Greece; koutsouris@aua.gr \\ 9 Institute of Sociology, Collegium Civitas, Warszawa 00-901, Poland; katarzyna.iwinska@civitas.edu.pl \\ * Correspondence: grzegorz.mikusinski@slu.se; Tel.: +46-70-77-57-161
}

Received: 11 September 2019; Accepted: 10 October 2019; Published: 12 October 2019

\begin{abstract}
One of the main challenges in sustainability discourse is its multifaceted nature often requiring that many different disciplines must cooperate in order to achieve progress. This issue also concerns sustainability education. In the article, we highlighted the experiences from the international cooperation of university teachers and researchers with highly diverse professional backgrounds who worked together on developing educational materials for university students in sustainability-oriented courses. The study is based on qualitative, participatory evaluation research, applying two rounds of open-ended questionnaires distributed to the same respondents $(n=18)$. For the analysis, we used the open-coding procedure for identifying the main categories. The results show some of the opportunities and barriers that emerged in the process of this cooperation. In particular, we discuss the issues related to the high heterogeneity of the group, such as the clashes of the different perspectives on the topics covered, group dynamics issues, trust, facilitation challenges, and also opportunities that such heterogeneity offers. We highlight the importance of open reflectivity in sustainability-oriented educational projects as the key to their successful implementation. Finally, we believe that results of this participatory study are useful in designing new projects aiming at further improvement of academic education in sustainability and sustainable development.
\end{abstract}

Keywords: international cooperation; higher education institutions; European project; educational resources; sustainability; diversity 


\section{Introduction}

There is an emerging and accumulating knowledge on how to develop academic courses and programs concerning sustainability and sustainable development [1-4]. The progress within this field is a reaction to the multifaceted and dynamic problems faced by humanity like climate change, poverty, biodiversity loss, or warfare, all being in critical need of solutions, and for which there are no obvious optimal solutions [5-7]. As such, sustainability education is an unceasing quest to find the best ways of teaching about these multifaceted and critical issues to present and future generations of students [5]. This quest has been formalized by the idea of Education for Sustainable Development (ESD) which is a vision of education that "seeks to empower people to assume responsibility for creating a sustainable future" [8]. Although the intentions and values of ESD have been discussed [9] and questioned by some scholars [10-12], ESD has evolved into an educational approach that is now used world-wide. Although the goals, content, and methods of ESD are not strictly defined, some features tend to dominate in its theoretical reflection and practice. ESD seeks to achieve societal transformation and meet global challenges $[13,14]$. Rather than setting specific objectives, ESD promotes general competences relevant for empowering people to take responsible action [3,15-17]. Although ESD points to global issues, it is often based on local needs [8]. Rather than awareness-based, it tends to be action-based. Students are encouraged to identify the unsustainable patterns in their community, to formulate a vision for the community's sustainable future, and to take action towards the vision's fulfillment. ESD resonates with concepts of the participative, emancipatory approach in which teachers become facilitators rather than truth-holders [18]. ESD is also often connected with community-based programs that draw on the concept of social learning in which community members learn from one another in the process of seeking resilience [19]. Although the implementation of ESD has been facing many challenges [20], there are encouraging examples of an achieved impact on student's environmental consciousness that is expected to pave the road towards sustainable development [4].

It could be argued that ESD in higher-education environments should follow the same pattern with opposition to change usually located at the individual level of teachers portrayed as reluctant to implementing innovative teaching because they are not aware of the research dimension that is valuable to their professional growth [21]. As a result, it calls for new and innovative forms of not only teaching but of all the processes of academic life, including student-teacher relations, university management, and curricula development. It demands the establishment of new teaching practices based on partnership and inter-disciplinary knowledge sources. In this respect sustainability education is particularly challenging due to complexity of problems it attempts to cover. Thus, it reinforces the need for learning and problem-solving, integrating a variety of disciplinary perspectives and insights [22-25]. The description of the multiplicity of such variations of 'cross-disciplinarity' and their organization into a coherent framework has become the focus of important theoretical contributions [26-31]. The need for adopting a cross-disciplinary approach for sustainable-development education has been raised by several authors [23,32-36] However, the mechanisms and outcomes of such an approach are still a matter of research [37].

This study we share the experiences from the international cooperation of university teachers and researchers with highly diverse professional backgrounds who worked together on developing educational materials for university students in sustainability-oriented courses.

\section{Theoretical Background and Aims of the Study}

\subsection{Cross-disciplinary Approaches}

As the boundaries between different areas of science have grown increasingly blurred, cross-disciplinary approaches have become more and more common [23]. For researchers getting involved in sustainability science, it includes the individual decisions about how to expand from one discipline to many disciplines required in cross-disciplinary collaboration [38]. Typically, collaboration that involves several disciplines is defined, along the continuum, as multidisciplinarity, 
interdisciplinarity, or transdisciplinarity. While multidisciplinarity refers to knowledge coming from several disciplines, respecting the limits of each discipline and not crossing the boundaries between them [39-41], interdisciplinarity emerges as a link and an intersection of the known bodies of different disciplines [40-42]. Finally, transdisciplinarity refers to the development of an overarching paradigm that encompasses a number of fields, it implies different roles of the various parties and brings together many worldviews, creating new ideas for exploration and better understanding [43-48]. As Putriene [49] summarizes, multidisciplinarity assumes work in several disciplines, interdisciplinary is a kind of junction between several disciplines, and transdisciplinarity goes beyond or across individual disciplines.

Diversity in multi-/ inter-/ transdisciplinary teams is often viewed positively, as one of the preconditions of social learning [50]. However, at the same time, it may become a source of barriers to successful collaboration [51]. According to Pennington [52], the integration of knowledge across disciplines is a difficult task. The process of cooperation across more fields of knowledge assumes a particular kind of openness on the part of the partners, openness to challenging the validity of their original beliefs and presuppositions [46]. This means that truly interdisciplinary cooperation may be a difficult process that "hurts" the participants [53]. Such openness also calls for a high level of actual disciplinary expertise to critically reflect on the basics of the field [53]. In contrast, the multidisciplinary approach offers a relatively safe environment for sharing expertise from different fields without the risk of confronting the horizons of the participants [46]. While multidisciplinarity assumes trusting the other partners and their expertise in their field, for an interdisciplinary approach, the ability to acquire and assimilate knowledge from different fields is an additional necessity [47].

As suggested above, the question of trust is a basic precondition for all of the forms of cross-disciplinarity. Trust is simply an essential precondition for any cooperation. According to Johnson and Johnson [54], this kind of trust is developed through the processes of being ready to take risks for the others, assuming openness and sharing, and being ready to accept risks when it is beneficial for the group, as well as assuming acceptance, support, and intention to cooperate. Such trust is developed when the risk offered by a group member is accepted by the others, and it is diminished when the risk is refused [54]. In terms of interdisciplinary cooperation, such a risk may be represented by questioning a problem under discussion from the perspective of a particular field, while the reaction of the others may be crucial for encouraging such behavior in the future. In addition, the group may struggle with other processes, such as negotiating the goals, competing for a position in the group, or setting effective communication rules [54]. These processes are often resolved in a series of struggles among the participants, usually soon after the start of their cooperation. The possible influence of group dynamics on the quality of interdisciplinary cooperation may call for careful facilitation [54]. Similarly, Penker and Muhar [55] mention the problem of power relations, trade-offs and the degree of participation (consultancy versus co-decision making) in transdisciplinary teams.

Cross-disciplinary cooperation presupposes the establishment of formal or informal social networks. Networks have been defined as "sets of formal and informal social relationships that shape collaborative action" between (heterogeneous) actors and "that transcend organizational structures and boundaries" [56] (p. 270). The social network is therefore about assembling the actors who take actions, share information and make choices. As a result, such assemblages provide a better framework (interactive structure) which allows the definition and redefinition of their members' interpretative paradigms and supports the process of structuring and empowering their identity. The actors integrate a number of interactions and elaborate on them, thus reshaping the views and perceptions of the actors. [57]. Davenport and Prusak [58] state that one of the characteristics of effective knowledge networks is neutral facilitation, Van Lente et al. [59] distinguish 'systemic intermediaries' i.e., actors working mostly at the system or network level to facilitate actor interactions. Haga [60] argues for the need to coordinate various enablers such as 'mediators' or 'brokers' who work as 'independent players' in networks. Their aims are to serve as points of passage to external stakeholders, add their expertise in, and, build internal network resources and network structure that influence the governance 
processes [61]. Nowadays, so-called innovation brokers, or 'facilitators of innovation' [59,62], are in general seen as useful for the innovation process due to reducing the number of system gaps and acting as animators or catalysts.

The cross-disciplinary approach in a university environment is a challenging and complex task. This is often attributed to the fact that traditional universities are organized according to disciplines that usually have powerful cultures and traditions. Thus, interdisciplinary work may bring difficulties when teachers/professors had received certification in a particular subject after going through an educator-preparation program that focused on their particular majors. This kind of education allows teachers/professors to teach in a specific discipline, but it makes it difficult for them to implement interdisciplinary instruction due to their own unpreparedness and misinformation regarding integrated knowledge [63]. This also means that scholars have strong loyalties, epistemological obligations, and discourses, unique interests, research practices as well as communication media. The latter has significant impact on professional and even personal identity $[27,64,65]$. Moreover, a cultural change is also considered essential to encourage universities to become more cross-disciplinary. This implies the rejection of individuality, elitism, the accumulation of benefit and academic territorialism relating to separation of disciplines and specialisations or, 'epistemic sovereignty' [66]. However, the competitive academic environment nowadays reinforces hostility to cross-disciplinary work [24].

Due to this situation, attaining cross-disciplinarity necessitates taking relevant initiatives that include the growth of enabling structures (both formal and informal possibilities for interaction, flexible, problem-driven groupings, and appropriate rewards and bonuses) as well as the development of skills $[67,68]$.

\subsection{Education for Sustainable Development (ESD)}

In higher education, multi- or interdisciplinarity may be applied as a strategy for teaching students [69-72] or as an approach to collaboration among a group of researchers from different fields [51,73,74]. As Annan-Diab and Molinari [23] summarize, interdisciplinary teaching is beneficial, but its implementation also brings certain barriers, such as demands on time, shared knowledge, or the skills needed for this kind of teaching and learning. Orozco and Cole [69] found that, for transdisciplinary health education for sustainable development (ESD) project, it was important to provide constant support of the field supervisor and promote interactions in the group. The inhibiting factors included the lack of training and the social pressure to apply a uni-disciplinary approach.

Albert et al. [73] investigated the experience of a group of social-sciences-and-humanities (SSH) scholars in the field of medicine. This process resulted in dissonance, with only a minority of the SSH scholars being unproblematically integrated. Van Dam-Mieras et al. [51] described some of the obstacles connected with interdisciplinary cooperation in relation to designing an international Master's program. Apart from the barriers emerging in a multi-language environment, they highlighted the importance of trust and mutual understanding as important factors for cooperation.

Similar issues were reported by Cebrián [22], who found the lack of a clear definition and common understanding of sustainability to be a recurring theme that proved a challenge for the cooperation of an interdisciplinary team working on promoting their ESD practice as university teachers. According to Činčera et al. [74], the processes of social learning in a diverse group of university teachers, members of non-governmental organizations and other stakeholders, were influenced by an interplay of personal and group contexts, the facilitation strategies applied, and the way the participants' experience was processed during their involvement in the project. This corresponds well with Cebrián [22], who found the role of a facilitator to be important for supporting the motivation and learning of the participating partners and who highlighted the role of reflection sessions and interactive group sessions.

Therefore, it may be possible to summarize that while the multi-/ inter-/ or trans-disciplinary approaches are expected to be among the essential features of the transformation of higher-education institutions towards effective teaching of sustainability, the process of their implementation is not straightforward and may bring certain challenges. 
In the last decade or so, the higher education institutions in Europe have been incorporating sustainable development into their curricula and have been perceived as a global leader in this regard $[75,76]$. Much of the current debate concerning the ESD in higher education institutions in Europe relates to the development of sustainability competencies among academic teachers. Capacity building that connects suitable pedagogical approaches with proper competences has been proposed to facilitate desired progress [77]. The interdisciplinary approaches to ESD in higher education institutions have been broadly studied and discussed $[20,23,77]$. In the European Union striving to attain common ground for making decisions concerning sustainability and sustainable development, the interdisciplinary approach must be supplemented with an ability to overcome barriers that arise from different cultural backgrounds. Overcoming cultural barriers is a prerequisite for the achievement of Sustainable Development Goals and successful ESD. Therefore, projects attempting to overcome challenges of cross-disciplinarity and cultural differences among participants are particularly interesting.

\subsection{This Study}

Among different mechanisms supporting the development of ESD in Europe is the economic support of international collaborative projects aiming at strengthening sustainability competencies among academic teachers e.g., in the frame of Erasmus+ programme [78]. The authors of this study were involved in the international educational project WISE (Widening Interdisciplinary Sustainability Education) funded by Erasmus+ programme in which scholars and university teachers from different disciplines cooperated on producing materials for teaching sustainability [79].

In this study, we analyze issues that emerged in the process of collaboration in our interdisciplinary and international team of scholars and teachers during the work on the various outputs of the WISE project. The main aim of the study was to analyze the process of participation in the project from the participants' perspectives on how to agree upon sustainable teaching. Specifically, the study is focused on the following questions: (1) How did the participants reflect the process of their cooperation from the perspective of existing diversity of the team? What problems and opportunities emerged? (2) What strategies do the participants consider to be the most beneficial ones for dealing with the diversity in the team?

In our study, we applied the concept of participatory evaluation that encompasses various possible perspectives of the process. We assumed that the results of our study could be useful in designing other international projects aiming at further improvement of academic education in sustainability and sustainable development.

\section{Materials and Methods}

The WISE Project (Widening Interdisciplinary Sustainability Education), was aimed at promoting the process of sustainable development of the participating partners in the field of higher education, as aligned with the 17 goals of the 2030 Agenda for Sustainable Development [80]. The objective of the WISE Project was to improve the general ability of the academic teachers and trainers to conduct interdisciplinary education focused on sustainability and to create an international interdisciplinary group of university teachers and researchers. Among the outcomes of the project was a handbook with some of the teaching materials (from both the social and the natural sciences) adapted to the needs of students as well as teachers [79], and also a new joint international innovative interdisciplinary educational program (Master's curricula). The partners of WISE were chosen for geographical and disciplinary diversity (Greece, Portugal, Czech Republic, Sweden, and Poland), specializations (agricultural economics, science education, ecology, environmental education, biodiversity conservation, political sciences/environmental sociology), and level of teaching experience (see Table 1). Basically, none of the other members of the WISE team had known each other before the project started. 
Table 1. Description of the project participants.

\begin{tabular}{cccccc}
\hline Participants (N) & Males & Females & Countries (N) & Ph.D. Students & Teachers \\
\hline 23 & 12 & 11 & 5 & 5 & 18 \\
\hline
\end{tabular}

The project lasted two years. While the members of the group were in occasional contact via email or the social platform Trello, their cooperation was facilitated mainly through four 5-day workshops (in different countries), three 2-day meetings organized by the different partners' universities, and periodic Skype meetings. While the attendance level varied, all the partners' universities were always represented by at least two members, and the national team leaders from each country were present at every meeting.

To evaluate our experience, we applied a participatory evaluation design. The concept of "participatory evaluation" encompasses various possible interpretations, ranging from utilization-focused evaluation [81] to different types of action research. We applied the following features of participatory evaluation [81-84]:

- The aim of the evaluation was not set at the beginning but allowed to emerge in the process,

- All of the respondents participated in designing the evaluation,

- The utilization of the findings remained the focal point of the study as it provided suggestions regarding how, on the basis of the reflected experience, future cooperation conducted in similar conditions could be shaped more effectively.

In the beginning, all the participants were asked to provide their responses to a set of open-ended questions in an online questionnaire. The focus of the questionnaires was defined by the group that agreed with the items, suggested by the first author [82]. In this phase, the evaluation was only generally focused on the participants' satisfaction with both the process and the outputs of the project and on identifying the main supporting factors and the main barriers to their cooperation. In total, we received eighteen responses $(n=18)$ out of the group of twenty-three participants in the project. Their responses were qualitatively analyzed and categorized according to a predetermined set of basic thematic categories (supporting factors, barriers, outputs, learning). The findings were summarized in the first draft of the evaluation report. To ensure the credibility of the findings, the report was sent to all of the respondents for their comments.

In the next step, all of the respondents were provided with an opportunity to continue their participation in the evaluation process. Twelve of the eighteen respondents declared their interest to do so. They were asked to provide their suggestions regarding the design of the follow-up research. Since the strongest category that had emerged during the previous step was diversity, the group decided to use this concept as the main focus of the research. When all the participants' ideas were incorporated, they were asked to provide their answers to a second online questionnaire, focusing specifically on how respondents perceived existing culture- and discipline- differences, group dynamic issues, and group effectiveness. The responses were qualitatively analyzed using an open-coding method in the Atlas.ti software. Finally, we identified two main categories (Diversity as an issue and Dealing with diversity) as the core of our findings. Subsequently, we added "Suggested strategies for dealing with diversity" as the additional category based on respondents' recommendations.

While this procedure followed some of the principles of grounded theory $[85,86]$, it also differed from this theory in some other aspects. Contrary to the grounded theory approach, we identified not only one but two mutually interconnected core categories describing the underlying social process in the group, i.e., group processes and project flow. Last but not least, the primary aim of the study was not an attempt to develop a new theory [87], but a practical utilization of the findings.

To increase credibility, all the respondents were given another opportunity to discuss the new findings. To protect the respondents' anonymity, all of their names were anonymized and replaced by the nicknames provided by the respondents. 
Our findings need to be interpreted in light of their limitations. The sample of respondents, while representing most of the part of project participants was considerably small. The quality of the analysis might have been further affected by the fact that the data were analyzed by the project team-members and so the evaluation lacks the perspective of other possible stakeholders (students, a donor) [84]. Also, the fact that the evaluation was done at the end of the project might influence some of the project team answers. While the participatory approach tends to be used for formative evaluation with the intention to improve the performance of an organization [87], this study also has some features of the summative evaluation as it was conducted after the closing of the project. However, the main aim was to provide insights gained from this experience to be used in future, follow-up projects.

Finally, while we believe that the participatory design of this study, involving the broad team of project members into the process of designing an evaluation, analyzing data, and even writing the manuscript has its own merit, it also provides considerable disadvantageous. It is reasonable to suppose that an external evaluation might bring more insight into the group processes and emerging issues. Regardless, we believe that the applied design highlighting correspondents with the participative nature of ESD and is suitable for this kind of analysis.

\section{Results}

\subsection{Diversity as An Issue}

Diversity emerged as the strongest theme in the respondents' reflection. While we can argue that diversity of team members is one of the crucial preconditions for multi-/inter-/trans-disciplinary cooperation, salient for ESD, it emerged as the main challenge of the teams' effective collaboration. The team was diverse in terms of the countries involved, the fields of specialization, the experience of the members, gender, and social status, and such a diversity was interpreted as both a benefit of the project and the main challenge. The ambivalent effect of diversity is well illustrated by the difference between the kinds of reflection of the respondents Mary and Alexis, one sees it as a clear advantage for the inter-disciplinarity of the project, while the other sees it as a threat for the project flow:

"I do not think that culture differences interfered in the group discussions, they enriched them. I think each country has its own context and the outputs should be a result of that mix. That can lead to longer discussions, although having a designated moderator can help to establish a platform for understanding." (Mary, female professor)

"Culture differences may severely interfere in the work of multinational (and multi-disciplinary) teams. Some cultures favor collaboration while others favor individualism. Different cultures may also nurture certain learning styles/patterns ( ... ) For example, some may wish to be involved in well-structured processes or even to be told what is expected of them while others love to explore issues and discuss them in-depth. Therefore, some may enjoy working in small groups and experimenting with new methods/techniques while others may consider such activities as a "waste of time and effort". (Alexis, male, professor)

Further, the differences in the perception of the project flow were influenced by diversity on an individual level. According to some of the respondents, the participants differed also in the level of their commitment to the project aims, and differences were found in their expectations, their personal experience with this kind of projects as well as their personal traits. As the social status of the team members ranged from university professors to PhD-students, some of the members were used to playing a leadership position, and, being confronted with a different perspective, they might have felt at risk of losing their position in the group. The differences in the perspectives of several of the project members even led to the difficulty of the group's general understanding and, naturally, subgroups were noticed sometimes.

"Most of us were scientists that (almost) by definition are very individualistic creatures with often a well-developed 'ego' and sometimes very strong opinions within your area of expertise. So, of course, 
there were some moments of irritation if somebody without the willingness to broaden the perspective tried to convince the others that something is simply 'the truth'. (... ) And, in such situations, obviously, some subgroupings could be observed." (Virgil, male professor)

The participants were surprised that their perspectives were not shared by the others and sometimes had a feeling that they were not accepted or treated equally. Distinct work methods also contributed to the barriers between the participants.

"It is difficult to have a dialogue if people do not understand each other or do not know each other well. So, the problem with cross-disciplinary cooperation is that the researchers were not prepared to tackle the issues from different perspectives. We all were also astonished by the differences as probably most of us believed that the main assumptions are clear (... ). After around the first six months (first workshop), we decided to ask each other questions and sometimes these questions were not nice (or were treated as quarreling)." (Vivi, female professor)

Being challenged by issues emerged as a result of the existing diversity, the team applied a set of consecutive strategies to deal with them.

\subsection{Dealing with Diversity}

\subsubsection{Avoiding Conflicts}

In the first months of the project, the group intuitively applied a strategy that helped to protect the group from conflicts owing to its diversity. As a result, the group tried to ignore existing differences in perspectives and preferred a polite and non-challenging style of work.

As the interdisciplinary communication was difficult and also because some of the respondents did not consider the need for a dialogue to be so crucial, part of the available time was spent (in the first part of the project) by top-down presentations of sustainability-oriented topics with a limited opportunity for sharing and reflecting. These, as one of the respondents called them, "futile monologues," were another reason for the slowing down of the flow of the project in its first phase.

Furthermore, the lack of opportunities for deeper debriefing sessions did not allow the resolution of already existing issues. As a result, the group spent a lot of time without real progress, which became a source of dissatisfaction of some of its members:

"We spent too much time listening to presentations that were not crucial for the project and its goals.

This time could have been used much more efficiently for discussing the issues of education for ESD or the methods that could be used." (Squirrel, male, PhD-student)

\subsubsection{Looking for a Common Ground}

Regardless of the "avoiding conflicts strategy", the group slowly realized the need to solve some of the emerging issues connected with its diversity. As the group realized, the tendency towards clashes was partly caused by the communication barriers caused by the differences in the communication codes used by the respondents:

"For some partners, it was important to have precise definitions of the terms and concepts employed, while others did not care that much about the terminology but focused on other things." (Squirrel, male, PhD-student)

However, the defining of terms and concepts was a particularly delicate subject. Some project members had different definitions for the same terms and concepts and others used the terminology in an inaccurate and inconsistent way. This led to the need for creating a glossary of the ESD-focused terms as part of the handbook output. According to Mary (female professor), the compilation of the glossary played an important role in the clarification and standardization of some of the definitions and concepts applied. However, as another respondent assumes, such a glossary did not work as the team members were rather "stuck" in their own disciplinary and experienced-based understanding. 


\subsubsection{Accepted Responsibility}

While the work of the group seemed to be slightly locked-down in the first half of the project, the project flow rapidly accelerated in the second year. The change was motivated by an external force, i.e., the necessity to finish the project outputs in time, and also by resolving some of the group-dynamics issues, as the group members became more familiar with one another and, as a result, the level of mutual trust and openness increased. With a higher level of mutual trust, the group members became less shy to challenge others' perspectives or accept feedback from other team members. Additionally, time spent together on workshops and meetings afterwards throughout the project enabled people to understand the differences and to tolerate the different roles played by members of the group.

Furthermore, the group started to accept their responsibility for the project outputs and their quality. Trust and accepted responsibility helped the group to achieve their goals, almost all the respondents considered the project as successful in the end. They expressed their satisfaction with the main part of the project outputs and reported a positive impact on their participation in their learning.

\subsection{Suggested Strategies for Dealing with Diversity}

On the basis of its reflected experience, the group formulated a few recommendations for dealing with diversity in sustainability-focused projects.

\subsubsection{Leadership is Crucial}

While most of the respondents highly appreciated the work of the project leader, some of them implicitly assumed that the task was, especially in the first part of the project, beyond the leader's abilities. According to some of the respondents, a more decisive approach was needed, one that would provide more opportunities for dealing with diversity in the group and the accompanying group-dynamics issues. Since such an approach calls for specific skills, some of the respondents recommended hiring an external facilitator.

"In general, as projects become more demanding in terms of partners (especially the multi-actor projects involving scientists from multiple backgrounds, practitioners, and other actors) and outputs (innovative deliverables), proper design (processes) and resources have to be put together. Within such planning, the role of facilitation has to be highlighted and thus pursued." (Alexis, male professor)

The task for such a facilitator should be paying attention to securing mutual understanding of the expectations and goals of the project, conducting evaluation (debriefing) after each session, providing enough time for discussion, splitting the team into smaller groups for some of the project activities, creating a safe space in which team members can discuss and resolve conflicts, and making time to reach agreement on what important and words, phrases, and concepts mean. This latter point is particularly important where the common language (English in this case) is a second language for many of the participants.

\subsubsection{Mindset is Important}

Accepting diversity means that the personal image of project members is at stake. Embracing diversity means demonstrating the courage to have one's own perspective challenged by the others and appreciating the differences in the group. As Maggie (female professor) comments,

"Accepting that each member had different backgrounds and different ways to deal with the same issues."

In order not to waste whole months, some of the respondents recommended finding common ground among the participants at the initial stage of the project: 
"One of the things I learned is to better appreciate differences and the importance of finding common ground. Even when universities are interested and invested in the same topics, their perceptions, perspectives, priorities and also cultural aspects might impact and sometimes constrain how the work is carried out." (Tina, female professor)

While there was no clear advice concerning the ways how to do this, some of the respondents suggested that a) as the consistency of the group matters, the initial selection of the partners for a project proposal plays an important role, and applicants experienced in multidisciplinary cooperation should be the core part of project' consortia, b) the organization of a special meeting focused on the integration of the project members may help them to find common ground when the project starts, and open discussion of the key issues requiring common understanding should be conducted at an early stage of the project.

\subsubsection{Time-frame Matters}

Last but not least, the right project design is crucial. Most of the respondents agreed that the project, taking into account its intensity, was too short and the time available (two years) was inadequate for establishing cooperation in diverse teams:

"Allow four years for the project instead of two, so that the group has the time necessary to overcome the barriers to effective collaboration and learn how to work as a team." (Bruin, male expert)

\section{Discussion}

While the findings must be interpreted in light of their methodological limitations (namely the small sample size and the lack of external perspective), we believe they could articulate potentially useful insights.

Viewed in the context of Putriene's [49] conceptualization, the approach applied by the WISE partners could be interpreted as a mixture of multi- and interdisciplinarity. The team worked in an easier, multidisciplinary mode in the first part of the project, and then in a more demanding, interdisciplinary mode in the second part. The multidisciplinary approach is the easiest way to work at a stage where the participants do not know one another well or are afraid to express their points of view or go beyond their disciplinary "comfort zone" and adapt to other working methods. An interdisciplinary mode was achieved only in the second part of the project when people already knew one another better and already knew how to respect or even challenge others' different working methods. Only then were the barriers of the different disciplines crossed and exchange of knowledge could begin. This may be explained by the opportunity to build trust in the first stage of the project so that interdisciplinary and cross-cultural cooperation was feasible in the second year. Agrawal [88] demonstrates that effective teamwork necessitates members to recognize the team as a unit with shared goals, values, and norms. Also, several researchers claim that trust is built up gradually, reinforced by previous trusting behavior and previous positive experiences [89-91].

One aspect that possibly helped in the process of trust-building was already existing engagement of participants in sustainability discourse and a common understanding that the project is dealing with very important questions and potentially may produce useful outputs. A study on higher education lecturers' in ESD revealed that a quite high level of support for sustainable development is visible across all discipline areas [92]. However, the same study also pointed out at a wide range of how sustainable development is understood among lecturers that leads to a high level of critical debate about the concept itself. Indeed, one of the issues being obstacle in smooth transition from often monodisciplinary backgrounds of participants in WISE-project towards functional interdisciplinary commitment, as pointed in evaluations, was different understanding of relevant terms including sustainability. Such problems have also been observed among scientists attempting to go beyond singular disciplines in inter- or transdisciplinary projects in sustainability research $[93,94]$. The need 
for change, openness, and flexibility in practice have been indicated as essential to ESD [95]. It requires extra effort from teachers and academics to go beyond their disciplinarily concerns [96].

The preference for the rather top-down approach prevailing in the first part of the collaboration could be also influenced by the lack of trust in the still not well-developed team [51]. The lack of willingness to challenge others' perspectives may mean that the group had just a limited opportunity to mature in terms of dealing with conflicts arising from the group's heterogeneity [97]. At the same time, the group did not make quick progress in developing an atmosphere in which constructive risk-taking would be met with acceptance, and so trust as a necessary precondition for deeper collaboration would develop [54].

The lack of time played an ambivalent role in the project. While the time-pressure forced the group to move on towards a more advanced mode of collaboration in the second part of the project, it was also reflected upon as a significant barrier [23]. Cross-disciplinary studies are known to be demanding with respect to time due to their complexity [98]. Dealing with power dynamics and creating an atmosphere of power equity is a complex and time-consuming process. Furthermore, some of the expected outcomes clearly called for a deep, interdisciplinary analysis, which it was impossible to accomplish in the given time-frame.

The findings further indicate a clash between managing the project from the perspective of its products versus its process-needs. It may be assumed that the orientation of project management towards products is, in a research world of milestones and outputs, still the dominant approach. However, this product-orientation calls for a different leadership style than a focus on the process and on the development of the participants' engagement. Dulewicz and Higgs [99] claim that "engaging leadership styles" perform better in transformational change projects, while they are less effective in a stable project environment. In contrast, goal-oriented leadership is considered to be more effective in relatively stable and context-significant change projects [100]. Because of this, the pressure on "outputs" might not only accelerate the project but also support leadership strategies providing fewer opportunities for dealing with the participants' engagement. The form of the main group interaction, i.e., 5-day workshops twice a year, was the mile-stone of the project in terms of approaching an interdisciplinary mode of work. However, this time was quite limited. In light of this, it could be recommended to organize project meetings of shorter duration. In addition, it seems to be reasonable to consider an opportunity for increasing the intensity of cooperation through the online environment. It is also important to notice that one of the communication instruments of the project, the Trello platform, was not mentioned by the respondents. This may indicate that this instrument was not seen as important and other, more effective, ways for facilitating communication would be needed. In light of this, establishing the position of a facilitator of regular online communication exchange, appointing someone who would systematically and frequently focus on online communication in the group, may bring additional benefits $[59,62]$.

There was a tremendous increase in speed and mutual understanding when the work on the first project output (the handbook) started and the group achieved a consent on common definitions. In light of this, it could be argued that when cooperation is focused on a specific output, it started to be more effective than when too much time spends on often un-focused but compulsory workshops.

Overall, the findings emphasize the importance of facilitators for providing groups with an opportunity to reflect and adjust the mechanisms of their cooperation [23,74]. A well-trained and experienced facilitator with interpersonal competence necessary to manage complex processes could be beneficial for this kind of project. The role of a facilitator seems to be important especially in the first part of a project when it can significantly help the group to establish an atmosphere of mutual trust and responsibility.

Communication problems clearly arose because of the use of disciplinary jargon and terms that mean different things to different people. The importance of seeking mutual understanding, especially at the early stage of the project, seems to be supported by both our findings and by the existing research [51]. This calls for a well-balanced, subtle approach, when the group must be able to openly 
discuss the differences in their understanding of a phenomenon, challenge the perspectives of the others, or present their own at a time when the group is still immature in many respects, the participants hardly know one another, and the atmosphere of trust has still not been fully developed. In light of this, while cross-disciplinarity is considered to be an effective response for sustainability challenges [22-25], its real implementation brings its own, specific challenges that need to be addressed by adequate means. Disciplinary cultures and traditions, as mentioned above $[24,27,64,65]$, shape professional and even personal identities, to this must be added the different institutional cultures which, in turn, largely shape the relevant skills that are required.

\section{Conclusions}

Our study focused on the process of cooperation of an inter-/ cross-disciplinary group of scholars and teachers from different countries and backgrounds in developing educational material for sustainability teaching. The most challenging aspect of this cooperation was the diversity itself and the associated need to open and challenge the horizons of each of the partners so as to be willing to consider different perspectives. As our findings imply, conflicts emerging from existing diversity are a natural part of ESD-oriented groups and an example of the social complexity that demands a different approach (based on core competencies for sustainability) to the design and implementation of sustainability interventions.

We conclude the analysis of this self- evaluation by main recommendations that follow. Firstly, the diversified group of well-established researchers/experts needs a common ground and facilitators that help, especially at the first stage of communication processes. Secondly, it is good to invest time and money into getting-to-know techniques for building trust among project's participants. Lastly, the leader or facilitator should remind and put attention on common aims so that members find additionally their own (internal) motivations towards achieving the project objectives.

We believe that experiences from our project presented in this paper will be useful in designing new projects aiming at further improvement of academic education in sustainability and sustainable development with various team members. Furthermore, we would like to highlight the importance of open reflectivity and willingness to change in sustainability-oriented educational projects as the key to their successful implementation.

Author Contributions: All authors have substantially contributed to the conceptualization of this study. J.C. has proposed methodology and performed formal analysis of the data. All authors have been involved in the data collection process. The first, not complete draft of the manuscript, was prepared by J.C. with help from A.K., C.V. and B.B. All authors have worked with reviewing and editing the earlier complete versions of the manuscript. The final editing of the submitted manuscript was performed by G.M. with help from J.C. and K.I. K.I. was responsible for funding acquisition and administration of WISE project on which the following study was based. The revision of manuscript was led by G.M. and J.C. with help from K.I. and all other authors.

Funding: This research was funded by European Commission within the frame of Erasmus Plus Project, grant number 2015-1-PL01-KA203-016621.

Conflicts of Interest: The authors declare no conflict of interest.

\section{References}

1. Tilbury, D. Environmental Education for Sustainability: Defining the new focus of environmental education in the 1990s. Environ. Educ. Res. 1995, 1, 195-212. [CrossRef]

2. Wals, A.E.J.; Jickling, B. "Sustainability" in higher education: From doublethink and newspeak to critical thinking and meaningful learning. Int. J. Sustain. Higher Ed. 2002, 3, 221-232. [CrossRef]

3. Wiek, A.; Withycombe, L.; Redman, C.L. Key competencies in sustainability: A reference framework for academic program development. Sustain. Sci. 2011, 6, 203-218. [CrossRef]

4. Pauw, J.B.; Gericke, N.; Olsson, D.; Berglund, T. The effectiveness of education for sustainable development. Sustainability 2015, 7, 15693-15717. [CrossRef] 
5. Cash, D.W.; Clark, W.C.; Alcock, F.; Dickson, N.M.; Eckley, N.; Guston, D.H.; Jager, J.; Mitchell, R.B. Knowledge systems for sustainable development. Proc. Natl. Acad. Sci. USA 2003, 100, 8086-8091. [CrossRef] [PubMed]

6. van Kerkhoff, L.; Lebel, L. Linking knowledge and action for sustainable development. Annu. Rev. Environ. Resour. 2006, 31, 445-477. [CrossRef]

7. Rowe, D. Education for a sustainable future. Science 2007, 317, 323-324. [CrossRef]

8. UNESCO Jakarta. Education for Peace and Sustainable Development; Regional Science and Bureau for Asia and the Pacific: Jakarta, Indonesia, 2016.

9. McKeown, R.; Hopkins, C. EE p ESD: Defusing the worry. Environ. Educ. Res. 2003, 9, 117-128. [CrossRef]

10. Robottom, I. Re-badbed Environmental Education: Is ESD more than just a slogan? S. Afr. J. Educ. 2007, 40, 90-96.

11. Kopnina, H. Education for sustainable development (ESD): The turn away from "environment" in environmen-tal education? Environ. Educ. Res. 2012, 18, 699-717. [CrossRef]

12. Kopnina, H.; Cherniak, B. Neoliberalism and Justice in Education for Sustainable Development: A call for inclusive pluralism. Environ. Educ. Res. 2016, 22, 825-841. [CrossRef]

13. UNESCO. What is ESD? 2016. Available online: https://en.unesco.org/themes/education-sustainabledevelopment/what-is-esd (accessed on 25 May 2019).

14. UNESCO. Education for Sustainable Development. 2016. Available online: https://en.unesco.org/themes/ education-sustainable-development. (accessed on 25 May 2019).

15. Rieckmann, M. Key competencies for a sustainable development of the world society. Results of a Delphi Study in Europe and Latin America. GAIA 2015, 20, 48-56. [CrossRef]

16. Rieckmann, M.; Kosler, T.; Holdsworth, S.; Thomas, I. Competencies, capabilities, skills, literacy ... ? Structuring debate around Education for Sustainable Development. In Proceedings of the European Conference on Educational Research 2014, Porto, Portugal, 2-5 September 2014.

17. Barth, M.; Godemann, J.; Rieckmann, M.; Stoltenberg, U. Developing key competencies for sustainable development in higher education. Int. J. Sustain. High. Educ. 2007, 8, 416-430. [CrossRef]

18. Wals, A.E.J.; Geerling-Eijff, F.; Hubeek, F.; van der Kroon, S.; Vader, J. All mixed up? Instrumental and emancipatory learning toward a more sustainable world: Considerations for EE policymakers. Appl. Environ. Educ. Commun. 2008, 7, 55-65. [CrossRef]

19. Waas, T.; Hugé, J.; Ceulemans, K.; Lambrechts, W.; Vandenabeele, J.; Lozano, R.; Wright, T. Sustainable Higher Education-Understanding and Moving Forward; Flemish Government-Environment, Nature and Energy Department: Brussels, Belgium, 2012.

20. Ashford, N.A. Major challenges to engineering education for sustainable development: What has to change to make it creative, effective, and acceptable to the established disciplines? Int. J. Sustain. High. Educ. 2004, 5, 239-250. [CrossRef]

21. Smith, E. Reflective reform in mathematics: The recursive nature of teacher change. Educ. Stud. Math. 1998, 37, 199-221. [CrossRef]

22. Cebrián, G. A collaborative action research project towards embedding ESD within the higher education curriculum. Int. J. Sustain. High. Educ. 2017, 18, 857-876. [CrossRef]

23. Annan-Diab, F.; Molinari, C. Interdisciplinarity: Practical approach to advancing education for sustainability and for the Sustainable Development Goals. Int. J. Manag. Educ. 2017, 15, 73-83. [CrossRef]

24. Koutsouris, A. Sustainability, crossdisciplinarity and Higher Education-From an agronomic point of view. J. US China Educ. Rev. 2009, 6, 13-27.

25. Junyent, M.; De Ciurana, A.M.G. Education for sustainability in university studies: A model for reorienting the curriculum. Br. Educ. Res. J. 2008, 34, 763-782. [CrossRef]

26. Nikitina, S. Three strategies for interdisciplinary teaching: Contextualizing, conceptualizing, and problem-centering. J. Curric. Stud. 2006, 38, 251-271. [CrossRef]

27. Aram, J. Concepts of interdisciplinarity: Configurations of knowledge and action. Hum. Relat. 2004, 57, 379-412. [CrossRef]

28. Lattuca, L.R. Creating Interdisciplinary: Interdisciplinary Research and Teaching among College and University Faculty; Vanderbilt University Press: Nashville, TN, USA, 2001.

29. Klein, J.T. Crossing Boundaries: Knowledge, Disciplinarities, and Interdisciplinarities; The University of Virginia Press: Charlottesville, VA, USA, 1996. 
30. Kockelmans, J.J. Why interdisciplinarity. In Interdisciplinarity and Higher Education; Kockelmans, J.J., Ed.; The Pennsylvania State University Press: University Park, PA, USA, 1979; pp. 123-160.

31. Jantsch, E. Towards interdisciplinarity and transdisciplinarity in education and innovation. In Interdisciplinarity: Problems of Teaching and Research in Universities; OECD: Paris, France, 1972; pp. 97-121.

32. Di Giulio, A.; Defila, R. Enabling university educators to equip students with inter- and transdisciplinary competencies. Int. J. Sustain. High. Educ. 2017, 18, 630-647. [CrossRef]

33. Dale, A.; Newman, L. Sustainable development, education, and literacy. Int. J. Sustain. High. Educ. 2005, 6, 351-362. [CrossRef]

34. Eagan, P.; Cook, T.; Joeres, E. Teaching the importance of culture and interdisciplinary education for sustainable development. Int. J. Sustain. High. Educ. 2002, 3, 48-66. [CrossRef]

35. Summers, M.; Childs, A.; Corney, G. Education for sustainable development in initial teacher training: Issues for interdisciplinary collaboration. Environ. Educ. Res. 2005, 11, 623-647. [CrossRef]

36. Brudermann, T.; Holländer, R.; Pastres, R.; Posch, A.; Schot, P. Integrating interdisciplinarity and internationality in sustainable development education. GAIA 2017, 26, 360-362. [CrossRef]

37. Biberhofer, P.; Rammel, C. Transdisciplinary learning and teaching as answers to urban sustainability challenges. Int. J. Sustain. High. Educ. 2017, 18, 63-83. [CrossRef]

38. Boda, C.S.; Faran, T. Paradigm found? Immanent critique to tackle interdisciplinarity and normativity in science for sustainable development. Sustainability 2018, 10, 3805. [CrossRef]

39. Alvargonzález, D. Multidisciplinarity, interdisciplinarity, transdisciplinarity, and the sciences. Int. Stud. Philos. Sci. 2011, 25, 387-403. [CrossRef]

40. Vasconcelos, C.; Faria, J. Case-based curricula materials for contextualized and interdisciplinary Biology and Geology learning. In Contextualizing Teaching to Improve Learning-The Case of Science and Geography; Leite, L., Dourado, L., Afonso, A.S., Morgado, S., Eds.; Nova Science Publishers: New York, NY, USA, 2017; pp. 245-260.

41. Choi, B.C.; Pak, A.W. Multidisciplinarity, interdisciplinarity and transdisciplinarity in health research, services, education, and policy: 1 . Definitions, objectives, and evidence of effectiveness. Clin. Investig. Med. 2006, 29, 351-364.

42. Karakus, M.; Uyar, M.Y. The implementation and evaluation of an instructional design based on the interdisciplinary approach: Conscious consumer education. J. Educ. Learn. 2017, 7, 65-75. [CrossRef]

43. Moore, J. Barriers and pathways to creating sustainability education programs: Policy, rhetoric and reality". Environ. Educ. Res. 2005, 11, 537-555. [CrossRef]

44. Lawrence, R.J.; Després, C. Futures of transdisciplinarity. Futures 2004, 36, 397-405. [CrossRef]

45. Jeffrey, P. Smoothing the waters: Observations on the process of cross-disciplinary research collaboration. Soc. Stud. Sci. 2003, 33, 539-562. [CrossRef]

46. Klein, J.T. Interdisciplinarity: History, Theory, Practice; Wayne State University Press: Detroit, MI, USA, 1991.

47. Klein, J.T. Typologies of interdisciplinarity: The Boundary Work of Definition. In The Oxford Handbook of Interdisciplinarity; Frodeman, R., Klein, J.T., Pacheto, R.C., Eds.; Oxford University Press: Oxford, UK, 2017; pp. 21-34.

48. Nowotny, H.; Scott, P.; Gibbons, M. Re-Thinking Science: Knowledge and the Public in an Age of Uncertainty; Polity Press: Cambridge, UK, 2001.

49. Putriene, N. Interdisciplinary Study Programmes: Controversies of Concept and Structure. Soc. Sci. 2014, 4, 70-77. [CrossRef]

50. Wildemeersch, D. Social learning revisited: Lessons learned from North to South. In Social Learning towards a Sustainable World; Wals, A.E.J., Ed.; Wageningen Academic Publishers: Wageningen, Netherlands, 2009; pp. 99-116.

51. Van Dam-Mieras, R.; Lansu, A.; Rieckmann, M.; Michelsen, G. Development of an interdisciplinary, intercultural master's program on sustainability: Learning from the richness of diversity. Innov. High. Educ. 2008, 32, 251-264. [CrossRef]

52. Pennington, D. A conceptual model for knowledge integration in interdisciplinary teams: Orchestrating individual learning and group processes. J. Environ. Stud. Sci. 2016, 6, 300-312. [CrossRef]

53. Jacobs, J.A. Defense of Disciplines: Interdisciplinarity and Specialization in the Research University; The University of Chicago Press: Chicago, IL, USA, 2013. 
54. Johnson, D.W.; Johnson, F.P. Joining Together. Group Theory and Group Skills; Pearson Allyn and Bacon: Boston, MA, USA, 2006.

55. Penker, M.; Muhar, A. What's actually new about transdisciplinarity? How scholars from applied studies can benefit from cross-disciplinary learning processes on transdisciplinarity. In Transdisciplinary Professional Learning and Practice; Gibbs, P., Ed.; Springer International Publishing: Cham, Switzerland, 2015; pp. $135-147$.

56. Dredge, D. Policy networks and the local organisation of tourism. Tour. Manag. 2006, 27, 269-280. [CrossRef]

57. Oliver, P.; Myers, J. Networks, Diffusion, and Cycles of Collective Action; Oxford University Press: Oxford, UK, 2003.

58. Davenport, T.; Prusak, L. Working Knowledge: How Organizations Manage What They Know; Harvard Business School Press: Cambridge, MA, USA, 1998.

59. Van Lente, H.; Hekkert, M.; Smits, R.; Van Waveren, B. Roles of systemic intermediaries in transition processes. Int. J. Innov. Manag. 2003, 7, 1-33. [CrossRef]

60. Haga, T. Orchestration of network instruments: A way to de-emphasize the partition between incremental change and innovation? Artif. Intell. Soc. 2009, 23, 17-31. [CrossRef]

61. Dhanaraj, C.; Parkhe, A. Orchestrating innovation networks. Acad. Manag. Rev. 2006, 31, 659-669. [CrossRef]

62. Winch, G.; Courtney, R. The organisation of innovation brokers: An international review. Technol. Anal. Strateg. Manag. 2007, 19, 747-763. [CrossRef]

63. You, H.S. Why teach science with an interdisciplinary approach: History, trends, and conceptual frameworks. J. Educ. Learn. 2017, 6, 66-77. [CrossRef]

64. Dewulf, A.; François, G.; Pahl-Wostl, C.; Taillieu, T. A framing approach to cross-disciplinary research collaboration: Experiences from a large-scale research project on adaptive water management. Ecol. Soc. 2007, 12, 14. [CrossRef]

65. Abbas, A.; McLean, M. Towards a Sociology of Teaching and Learning: Politicising Pedagogic Praxis? 2002. Available online: http://escalate.ac.uk/resources/disabledstudentsinhe/ (accessed on 22 May 2018).

66. Healy, S. Epistemological pluralism and the 'politics of choice'. Futures 2003, 35, 689-701. [CrossRef]

67. Russell, W.; Wickson, F.; Carew, A. Transdisciplinarity: Context, contradictions and capacity. Futures 2008, 40, 460-472. [CrossRef]

68. Horlick-Jones, T.; Sime, J. Living on the border: Knowledge, risk and transdisciplinarity. Futures 2004, 36, 441-456. [CrossRef]

69. Orozco, F.; Cole, D.C. Development of transdisciplinarity among students placed with a sustainability for health research project. EcoHealth 2008, 5, 491-503. [CrossRef]

70. Kaur, S.; Manan, S.A. Developing interdisciplinary teaching: A vignette of a postgraduate course. Procedia Soc. Behav. Sci. 2013, 90, 755-763. [CrossRef]

71. Stewart, M. Transforming higher educations: A practical plan for integrating sustainability education into the student experience. J. Sustain. Ed. 2010, 1, 195-203.

72. Grierson, D.; Munro, K. Transformative learning methods in interdisciplinary postgraduate education for sustainable development (ESD). Archnet-IJAR 2018, 12, 209-227. [CrossRef]

73. Albert, M.; Paradis, E.; Kuper, A. Interdisciplinary promises versus practices in medicine: The decoupled experiences of social sciences and humanities scholars. Soc. Sci. Med. 2015, 126, 17-25. [CrossRef] [PubMed]

74. Činčera, J.; Biberhofer, P.; Binka, B.; Boman, J.; Mindt, L.; Rieckmann, M. Designing a sustainability-driven curriculum as a social learning process. A case study from an international knowledge alliance project. J. Clean. Prod. 2018, 172, 4357-4366. [CrossRef]

75. Disterheft, A.; Ferreira da Silva Caeiro, S.S.; Ramos, M.R.; de Miranda Azeiteiro, U.M. Environmental Management Systems (EMS) implementation processes and practices in European higher education institutions-Top-down versus participatory approaches. J. Clean. Prod. 2012, 31, 80-90. [CrossRef]

76. Lozano, R.; Ceulemans, K.; Alonso-Almeida, M.; Huisingh, D.; Lozano, F.J.; Waas, T.; Lambrechts, W.; Lukman, R.; Hugé, J. A review of commitment and implementation of sustainable development in higher education: Results from a worldwide survey. J. Clean. Prod. 2014, 108, 1-18. [CrossRef]

77. Lozano, R.; Barreiro-Gen, M.; Lozano, F.J.; Sammalisto, K. Teaching sustainability in European higher education institutions: Assessing the connections between competences and pedagogical approaches. Sustainability 2019, 11, 1602. [CrossRef] 
78. EU. In the Spotlight: Supporting Sustainable Development in Education. Available online: https://ec.europa. eu/programmes/erasmus-plus/anniversary/spotlight-supporting-sustainable-development-education_en (accessed on 29 August 2019).

79. Iwińska, K.; Jones, M.; Kraszewska, M. (Eds.) Widening Interdisciplinary Sustainability Education; Collegium Civitas: Warszawa, Poland, 2018.

80. UN. Transforming our World: The 2030 Agenda for Sustainable Development. Resolution adopted by the General Assembly on 25 September 2015. A/RES/70/1. 2015. Available online: https:/www.un.org/ga/search/ view_doc.asp?symbol=A/RES/70/1\&Lang=E (accessed on 29 August 2019).

81. Patton, M.Q. Utilization-Focused Evaluation; Sage Publications: London, UK, 2008.

82. Mertens, D.M.; Wilson, A.T. Program Evaluation Theory and Practice. A Comprehensive Guide; The Guilford Press: New York, NY, USA, 2012.

83. Remr, J. Participativne zalozene evaluacni pristupy (Participatory Evaluation Approaches). Evaluacni Teorie a Praxe 2015, 3, 79-100.

84. Cousins, J.B.; Earl, L.M. The case for participatory evaluation. Educ. Eval. Policy Anal. 1992, 14, $397-418$. [CrossRef]

85. Glaser, B.G. Doing Grounded Theory: Issues and Discussions; Sociology Press: Mill Valley, CA, USA, 1998.

86. Charmaz, K. Constructing Grounded Theory_Practical Guide Through Qualitative Analysis; Sage Publications: Thousand Oaks, CA, USA, 2006.

87. Springett, J.; Wallerstein, N. Issues in Participatory Evaluation. In Community-Based Participatory Research for Health: From Process to Outcomes; Minkler, M., Wallerstein, N., Eds.; Jossey-Bass: San Francisco, CA, USA, 2008; pp. 199-215.

88. Agrawal, V. Managing the diversified team: Challenges and strategies for improving performance. Team Perform. Manag. Int. J. 2012, 18, 384-400. [CrossRef]

89. McAllister, D.J. Affect- and cognition-based trust as foundations for interpersonal cooperation in organizations. Acad. Manag. J. 1995, 38, 24-59.

90. Lewicki, R.J.; Bunker, B.B. Developing and maintaining trust in work relationships. In Trust in Organizations, Frontiers of Theory and Research; Kramer, R.M., Tyler, T.R., Eds.; Sage Publications: Thousand Oaks, CA, USA, 1996; pp. 114-139.

91. Six, F.E. Building interpersonal trust within organizations: A relational signaling perspective". J. Manag. Gov. 2007, 11, 285-309. [CrossRef]

92. Cotton, D.R.E.; Warren, M.F.; Maiboroda, O.; Bailey, I. Sustainable development, higher education and pedagogy: A study of lecturers' beliefs and attitudes. Environ. Educ. Res. 2007, 13, 579-597. [CrossRef]

93. Stock, P.; Burton, R.J.F. Defining terms for integrated (multi-inter-trans-disciplinary) sustainability research. Sustainability 2011, 3, 1090-1113. [CrossRef]

94. Thomas, I. Challenges for implementation of education for sustainable development in higher education institutions. In Routledge Handbook of Higher Education for Sustainable Development; Barth, M., Michelsen, G., Thomas, I., Rieckmann, M., Eds.; Routledge: London, UK, 2016; pp. 56-71.

95. Sammalisto, K.; Sundström, A.; Holm, T. Implementation of sustainability in universities as perceived by faculty and staff - a model from a Swedish university". J. Clean. Prod. 2015, 106, 45-54. [CrossRef]

96. Cebrián, G.; Grace, M.; Humphris, D. Academic staff engagement in education for sustainable development. J. Clean. Prod. 2015, 106,1-16. [CrossRef]

97. Watson, J.C. Mapping patterns of change in emotion-focused psychotherapy: Implications for theory, research, practice, and training. Psychother. Res. 2018, 28, 389-405. [CrossRef]

98. Canter, M.; Brumar, C.I. Transdisciplinary niches fostering Lifelong Learning. Procedia Soc. Behav. Sci. 2011, 28, 636-639. [CrossRef]

99. Dulewicz, V.; Higgs, M.J. Design of a new instrument to assess leadership dimensions and styles. In Henley Working Paper Series HWP 0311; Henley Management College: Henley-on-Thames, UK, 2003.

100. Turner, J.R.; Müller, R. The project manager's leadership style as a success factor on projects: A literature review. Proj. Manage. J. 2005, 36, 49-61. [CrossRef]

(C) 2019 by the authors. Licensee MDPI, Basel, Switzerland. This article is an open access article distributed under the terms and conditions of the Creative Commons Attribution (CC BY) license (http://creativecommons.org/licenses/by/4.0/). 